8 Hirst LW, Waring GO. Clinical specular microscopy of posterior polymorphous endothelial dystrophy. Am f Ophthalmol 1983; 95: 143-55.

9 Sherrard ES, Frangoulis MA, Kerr Muir MG, Buckley RJ. The posterior surface of the cornea in the irido-corneal endothelial syndrome: a specular surface of the cornea in the irido-corneal endothelial syndrome: a
microscopical study. Trans Ophthalmol Soc UK 1985; 104: 766-74.

10 Laganowski H, Sherrard ES, Kerr Muir MG, Buckley RJ. Distinguishing features of the irido-corneal endothelial syndrome and posterior polymorphous dystrophy: value of endothelial specular microscopy. BrF Ophthalmol 1991; 75: 212-6.

11 Hirst LW. Differential diagnosis of iridocorneal endothelial syndrome and posterior polymorphous endothelial dystrophy. Kerr-Muir MG, Laganowsk HC, Buckley RJ. Reply. [Letters.] Br f Ophthalmol 1993; 77: 610.

12 Hirst LW, Green WR, Luckenbach M, de la Cruz Z, Stark WJ. Epithelial characteristics of the endothelium in Chandler's syndrome. Invest Ophthalmo Vis Sci 1983; 24: 603-11.

13 Rodrigues MM, Stulting RD, Waring GO. Clinical, electron microscopic, and immunohistochemical study of the corneal endothelium and Descemet's membrane in the iridocorneal endothelial syndrome. Am $\mathcal{F}$ Ophthalmol 1986; 101: $16-27$.

14 Alvarado JA, Murphy CG, Maglio M, Hetherington J. Pathogenesis of Chandler's syndrome, essential iris atrophy and the Cogan-Reese syndrome.
1. Alterations of the corneal endothelium. Invest Ophthalmol Vis Sci 1986; 27: 853-72.

15 Kramer TR, Grossniklaus HE, Vigneswaran N, Waring GO, Kozarsky A Cytokeratin expression in corneal endothelium in the iridocorneal endothelial syndrome. Invest Ophthalmol Vis Sci 1992; 33: 3581-5.

16 Levy SG, Moss J, Baghai M, Barrett M, McCartney ACE. Studies on the aetiology of the iridocorneal endothelial syndrome: the origin of the ICE cell. Invest Ophthalmol Vis Sci 1994; 35: 2757 (ARVO abstracts).

7 Alvarado JA, Murphy CG, Juster RP, Hetherington J. Pathogenesis of Chandler's syndrome, essential iris atrophy and the Cogan-Reese syndrome. 2. Estimated age at disease onset. Invest Ophthalmol Vis Sci 1986; 27:873-82.

18 Alvarado JA, Wu S, Yun AJ, Nguyen TD, Hwang DG, O'Day D, et al. Detection of herpes simplex I viral DNA in the ICE syndromes using the polymerase chain reaction. Invest Ophthalmol Vis Sci 1991; 724 (ARVO Abstracts).

19 Tsai CS, Ritch R, Straus SE, Perry HD, Hsieh FY. Antibodies to Epstein-Barr virus in iridocorneal endothelial syndrome. Arch Ophthalmol 1990; 108: $1572-6$.

20 Alvarado JA, Underwood JL, Green WR, Wu S, Yun AJ, Murphy CG, et al. Further studies to substantiate a viral etiology for the ICE syndrome. Invest Ophthalmol Vis Sci 1993; 1435 (ARVO Abstracts).

\title{
Mechanisms governing the passage of aqueous humour through the trabecular meshwork
}

Ascher's discovery of aqueous veins half a century $\operatorname{ago}^{1}$ was the crucial factor in recognising that aqueous humour is a circulating fluid draining from the anterior chamber, and a few years later Ashton demonstrated continuity between the canal of Schlemm and aqueous veins. ${ }^{2}$ The trabecular meshwork at the iridocorneal angle was the obvious route for drainage, yet for this to be so the continuous endothelial layer constituting the inner wall of the canal of Schlemm had to be breached. With the aid of electron microscopy, Holmberg ${ }^{3}$ and Tripathi ${ }^{4}$ advanced the concept that this was achieved by means of giant vacuole transport (earlier light microscopic observations had suggested the possibility). Pores on the abluminal surface develop into giant vacuoles up to $3 \mu \mathrm{m}$ in diameter, contact the luminal surface, and discharge into the canal. The incidence and size of giant vacuoles are intraocular pressure dependent, ${ }^{56}$ and measurement of pressure in each of the structures involved in aqueous drainage confirmed the meshwork as the principal site of resistance to outflow. ${ }^{7}$ Some paracellular drainage through the leaky gap junctions of the inner wall is likely ${ }^{8}$ but probably very limited. ${ }^{9}$ The juxtacanalicular tissue adjacent to the inner wall, consisting of a mesh of endothelial cells within a loose fibrous matrix, may have the major role in trabecular resistance to aqueous humour outflow. ${ }^{10}$ According to this view the facility of passage through the juxtacanalicular tissue determines access of aqueous to the inner wall and, consequently, the rate of formation and discharge of giant vacuoles. Provided the wide channels of the deeper parts of the meshwork are maintained, their potential for obstruction appears negligible, especially when the spacing of the beams is viewed with the scanning electron microscope. But Carreras and his colleagues ${ }^{11}$ have reopened the debate of the significance of mucous cover of trabecular cell membranes ${ }^{12}$ by identifying a substantial mucous lining of the posterior and anterior chambers in humans, thickest at the filtration angle. They suggest that its glycosaminoglycan composition, containing long hyaluronic acid molecules, is capable of trapping and holding virtually any of the macromolecules suspended in aqueous and so plays a part in the regulation of aqueous outflow.

Recently, attention has been directed to the subject of endothelial cell permeability and in particular to the role of negatively charged domains (anionic sites) on membrane surfaces. Sialic acid groups, highly charged anions, are the terminal constituents of many cell surface glycoconjugates for example, gangliosides and glycoproteins such as fibronectin and laminin. Consequently, they are important in the maintenance of structural relations between endothelium and matrix and they are thought to be a factor in the stabilising of cell membranes. Using cationic ferritin and colloidal iron labelling coupled with neuraminidase digestion, sialic acid groups have been identified on each side of the lining endothelium of Schlemm's canal. Labelling was heavy on the luminal surface but random and sparse on the abluminal or basal surface. ${ }^{13}$ In this issue of the journal Chapman and colleagues report their work confirming a concentration of sialyl groups on the luminal surface and, furthermore, employing a method using different cationic probes to distinguish two sialyl glycosides, one of them disposed mainly on the luminal aspect of the lining endothelium and in the cytoplasm of juxtacanalicular tissue cells. The other was localised predominantly to the extracellular fibrillar material of this region. The demonstration of different sialyl glycosides occupying distinct sites in the trabecular meshwork adds further encouragement to the proposal that they are of significance in the regulation of aqueous outflow. The argument is presented that absence or sparseness of sialated molecules on the abluminal surface of the lining endothelium reduces membrane stability, facilitating initiation of the macrovacuolisation process and, thus, aqueous passage. Interest is heightened by the observation of increased labelling on both sides in glaucoma, ${ }^{13}$ presumably increasing stability and reducing capacity for giant vacuole formation. Observations in other studies are not consistent with this result and it becomes clear that the effects of differences in tissue preparation must be understood before there is further progress. ${ }^{14}$ Future monitoring of the response to selective manipulation of these and other anionic sites and the potential for their therapeutic regulation are exciting prospects.

GORDON RUSKELL

Department of Optometry and Visual Science,

City University, London ECIV 7DD

1 Ascher KW. Aqueous veins. Am f Ophthalmol 1942; 25: 31-8.

2 Ashton N. Anatomical study of Schlemm's canal and aqueous veins by means of neoprene casts. Br f Ophthalmol 1951; 32: 291-303. 
3 Holmberg A. Schlemm's canal and trabecular meshwork: an electron microscopic study of the normal structure in man and monkey (Cercopithecus ethiops). Doc Ophthalmol 1965; 19: 339-73.

4 Tripathi RC. Ultrastructure of Schlemm's canal in relation to aqueous outflow. Exp Eye Res 1968; 7: 335-41.

5 Johnstone MA, Grant WM. Pressure dependent changes in structure of the aqueous outflow system of human and monkey eyes. Am $\mathcal{F}$ Ophthalmol 1973; 75: $365-83$.

6 Grierson I, Lee WR. Changes in the monkey outflow apparatus at graded levels of intraocular pressure: a qualitative analysis by light microscopy and

7 Mäepea O, Bill A. The pressure in the episcleral veins, Schlemm's canal and the trabecular meshwork in monkeys: effect of changes in intraocular pressure. Exp Eye Res 1989; 49: 645-63.

8 Epstein D, Rohen JW. Morphology of the trabecular meshwork and inner wall endothelium after cationized ferritin perfusion in the monkey eye. Invest Ophthalmol Vis Sci 1991; 32: 160-71.
9 Raviola G, Raviola E. Paracellular route of aqueous outflow in the trabecular meshwork and canal of Schlemm. Invest Ophthalmol Vis Sci 1981; 21: 52-72.

10 Bill A, Svedbergh B. Scanning electron microscopic studies of the trabecular meshwork and the canal of Schlemm: an attempt to localise the main resistance to outflow of aqueous humour in man. Acta Ophthalmol 1972; 50: resistance 320 .

11 Carreras FJ, López Caballero JJ, Porcel D. A gel of glycosaminoglycans lining the anterior and posterior chambers in man. Histochemical evidence at the light and electron microscopical levels. Eye 1992; 6: 574-82.

12 Grierson I, Lee WR. Acid mucopolysaccharides in the outflow apparatus. Exp Eye Res 1975; $21: 417-31$

13 Tripathi RC, Tripathi BJ, Spaeth GL. Localization of sialic acid moieties in the endothelial lining of Schlemm's canal in normal and glaucomatous eyes. Exp Eye Res 1987; 44: 293-306.

14 De Kater AW, Melamed S, Epstein DL. Patterns of aqueous humor outflow in glaucomatous and non-glaucomatous human eyes: a tracer study using cationized ferritin. Arch Ophthalmol 1989; 107: 572-70. 